\title{
Self-Care in Type 2 Diabetes Patients with
}

\section{Urgency Lower Limb Amputation: The Influence of Sex, Marital Status and Previous Amputations}

\author{
Simone Aparecida Domingos' \\ Carolina Nunes França' \\ Izabela Tuleta ${ }^{2}$ \\ Marianne Penachini da Costa \\ Rezende Barbosa ${ }^{3}$ \\ Andre Luis Lacerda Bachi (iD) \\ Lucas Melo Neves (iD) ${ }^{1,4}$ \\ 'Program in Health Sciences, Santo \\ Amaro University, São Paulo, Brazil; \\ ${ }^{2}$ Department of Cardiology I, University \\ Hospital Muenster, Muenster, Germany; \\ ${ }^{3}$ Educational Foundation of the \\ Municipality of Assis (FEMA) and \\ Universidade, Estadual Paulista (UNIP), \\ Assis, Brazil; ${ }^{4}$ Bipolar Disorder Program \\ (PROMAN), Department of Psychiatry, \\ University of São Paulo Medical School, \\ São Paulo, Brazil
}

Aim: Lower limb amputation (LLA) is a severe consequence of type 2 diabetes mellitus (T2DM), and can affect up to $1 \%$ of T2DM patients, leading to an increased risk of premature mortality. Among the factors to predict LLA, it has been highlighted sex, marital status, and previous amputation. However, there is a lack of information about the association between these predictive factors, self-care, and urgency LLA in T2DM patients.

Purpose: To verify the behavior of self-care and to relate it with the predictive factors (sex, marital status, and previous amputation) in urgency LLA T2DM patients.

Patients and Methods: Non-interventional study, with 106 T2DM patients who were in the postoperative period of urgency LLA caused by complications resulting from T2DM. A structured questionnaire was used for sociodemographic and clinical characterization of the sample as well as the Summary of Diabetes Self-Care Activities (SDSCA) tool. It was used the Wilcoxon, Friedman, and Mann-Whitney tests (median, nonparametric populations) to assess the significance of the differences between groups (sex, marital status, and previous amputation), also Spearman correlation coefficient to assess the association between the data (comparison between diagnostic time, sex, previous amputation, ethnicity and systolic arterial hypertension) and a logistic regression analysis considering the item SDSCA related to sex, age and marital status (with partner).

Results: Significant differences $(\mathrm{p}<0.05)$ in the questions "Specific Food" and "Foot care" were found when the participants were grouped by sex. In the relation to marital status, significant differences $(p<0.05)$ were observed for the question "Specific Food". No differences were found between groups with or without previous amputation.

Conclusion: By SDSCA tool, we were able to report that T2DM patients submitted to urgency LLA presented differences in self-care, particularly for sex and marital status.

Keywords: self-care activities, surgery, diabetes mellitus, food, foot care

\section{Introduction}

Diabetes mellitus (DM) is caused by the body's lack of ability to produce or use insulin. ${ }^{1}$ Two principal forms of DM have highlighted: type 1 DM (T1DM), which corresponds to $5 \%$ to $10 \%$ of cases and type 2 DM (T2DM), corresponding to $90 \%$ to $95 \%$ of cases. ${ }^{2,3}$ The DM annual number in the world in 2025 is projected to be 26.6 million - global incidence; 570.9 million - prevalence; 1.59 million - death; and 79.3 million - disability-adjusted life-years. ${ }^{4}$ Important alterations can be observed in patients with DM, such as infection, ulceration, or destruction of tissues of the foot, which affect more than $6 \%$ of diabetic patients. ${ }^{5}$
Correspondence: Lucas Melo Neves Program in Health Sciences, Santo Amaro University, Rua Prof. Enéas de Siqueira Neto, 340. Building FI - Health Sciences Room - Jardim Das Imbuias, São Paulo, SP, 04829-300, Brazil

Tel +55 II 2 I $4 \mid-8584$

Email lucasmeloneves@uol.com.br 
Foot ulcers in diabetic patients are accompanied by a higher risk when compared to no foot ulcers, and approximately one in five of these patients require some level of amputation. ${ }^{6}$ Lower limb amputation (LLA) is a serious consequence of the infection, ulceration, or destruction of tissues and can affect up to $1 \%$ of diabetic patients, ${ }^{7,8}$ resulting in a decrease in quality of life and an increased risk for premature mortality. ${ }^{9}$ Useful strategies to reduce LLA in T2DM patients are foot monitoring and self-recognition of the early signs of diabetic foot complications. ${ }^{10}$ At this sense, recent guidelines recommend patient education and daily foot monitoring by T2DM patients. ${ }^{11}$

Patient education can be important for the development of self-care, which can be understood as the set of activities that involve dietary, corporal, drug, and glucose monitoring practices performed by the patient in order to promote a satisfactory healthy status. ${ }^{12}$ In this context, seven items are important in self-care and self-control in T2DM: healthy coping, healthy eating, being active, taking medication, monitoring, reducing risk, and problemsolving. ${ }^{13}$

As summarized in a recent meta-analysis, among different factors to predict amputation, it has been highlighted: sex, previous amputation, and marital status. ${ }^{14}$ However, there is a lack of information about the association between these predictive factors, self-care, and urgency LLA in T2DM patients.

Therefore, in this study, we verified the behavior of selfcare in T2DM patients in urgency LLA and its association with the predictor factors, considering sex, previous amputation, and marital status. A better knowledge of the influence of these outcomes is critical to enable multidisciplinary teams to develop management and interventions to prevent the need for urgency LLA in T2DM patients.

\section{Materials and Methods Study Design}

This is a non-interventional study, with 106 patients previously diagnosed with T2DM, in the postoperative period of urgency (not provided occurrence with or without potential risk to life, where the individual needs immediate medical assistance) LLA caused by complications resulting from T2DM, at a public Hospital, located on the east side of São Paulo city, Brazil. LLA was considered minor and major amputations (pododactilos, transmetataric, transtibial and transfemoral). The recruitment and selection of the patients enrolled in this study followed these criteria: amputation for reasons unrelated to T2DM or performance of an elective amputation; failing to answer the questions in the proposed questionnaires; disagreement to participate in the research in the research. Patients who agreed to participate voluntarily in the study were oriented to sign the informed consent previously approved by the Ethics and Research Committee of Santo Amaro University and Hospital Municipal Doutor Cármino Caricchio and was conducted in accordance with the Declaration of Helsinki.

\section{Data Collection Instruments}

A structured questionnaire with sociodemographic (including name, age, sex, ethnicity/color, marital status, and work occupation) and clinical characterization data (history of previous amputation, time of T2DM manifestation, systemic arterial hypertension, smoking, use of antibiotic therapy prior to the current amputation, ulcerative injury mechanism, and amputation level) was applied to the participants.

In addition, to assess self-care activities, a questionnaire on self-care activities with diabetes, ${ }^{15}$ formerly adapted, and validated for the Brazilian population, ${ }^{16}$ from the American version of the Summary of Diabetes Self-Care Activities (SDSCA) was used. ${ }^{15}$ The Brazilian version of the SDSCA is available in open access original paper, and can be used with correct citation of original paper, ${ }^{16}$ and consists of six dimensions and 15 items for self-care assessment with DM distributed as follows: general food (two items), specific food (three items), physical activity (two items), blood glycemia monitoring (two items), foot care (three items), and use of medication (three items used according to the drug therapy adopted), as well as an additional assessment on smoking, containing three items. ${ }^{16}$ The questions address diabetes care during the seven days immediately before the interview or seven days before the health condition have worsened and require surgical intervention. The responses are parameterized on days of the week, with responses from zero to seven days, with zero corresponding to a worse picture of adherence, and seven the most favorable situation. In the specific food dimension, for items 2.2 and 2.3, which ask about the consumption of foods rich in fats and sweets, respectively, the values are reversed; the greater the number of days of consumption of these foods, the worse the adherence. In the additional item that assesses smoking, the proportion of smokers, the average number 
of cigarettes per day, and the last time the individual smoked are considered.

\section{Statistical Analysis}

Data were analyzed using IBM SPSS Statistics, version 22 (SPSS Inc., Chicago, IL, USA). Distributions of continuous variables were tested for normality using the ShapiroWilk test and for equality of variances using Levene's test. Quantitative variables with symmetric distribution are described as means and standard deviations and asymmetric distribution as medians and interquartile range. To assess the differences between groups, the Wilcoxon, Friedman, and Mann-Whitney tests (median, nonparametric populations) were used. For association data (comparison between diagnostic time, sex, previous amputation, ethnicity, and SAH) we used Spearman correlation coefficient. A logistic regression was performed to verify the relation between binary categorical variables and continuous (domains of the self-care questionnaire) and categorical predictors (sex, age, or marital status). A p-value $\leq 0.05$ was considered the threshold of statistical significance.

\section{Results}

Table 1 shows the data of the sample characteristics considering the groups divided by sex, Marital Status and Previous amputation. Information regarding Ethnicity/ color, Work occupation, Systolic arterial hypertension, Smoking, Years of diagnosis and Amputation level are described.

Table 2 shows the comparison between groups performed by the Mann-Whitney tests considering sex (men and women), marital status (with partner or without partner), and previous amputation (yes or no). Differences were found in the comparisons Marital Status [for question Specific Food - sub-item 2.2 Eating high-fat foods, meat and/or whole milk products - median was $2.2(0-4)$ for people with partner and $3.5(0-7)$ for people without a partner $-\mathrm{p}<0.05]$. In addition, another significant difference was observed when the participants were grouped according to sex [for question Specific Food - sub-item 2.1 Eating five or more servings of fruits and/or vegetables - median 4.0 (3-7) male and $7.0(3-7)$ female $-\mathrm{p}<0.05$ and for question Foot-care (sub-item 5.3 Dry the spaces between the toes, after washing them) median $7.0(0-7)$ men and $5.0(0-7)$ women $-\mathrm{p}<0.05]$.

Table 3 shows the logistic regression analysis considering the item SDSCA related to Sex, Age and Marital
Status (with partner). The results showed dependence related to eating high fat food meat and/or whole milk products (sub-item 2.2) and eating sweets (sub-item 2.3) $(\mathrm{p}=0.028$ and $\mathrm{p}=0.058$, respectively). This sub-analysis reaffirms the importance of self-care in relation to food in the verified sample.

\section{Discussion}

The results obtained in the present study regarding the self-care in T2DM patients with urgency LLA, verified by the SDSCA, showed there is no difference between self-care and previous or not previous amputation. On the other hand, the Marital Status showed a significant difference when comparing people with and without partner [for question Specific Food - sub-item 2.2 Eating highfat foods, meat and/or whole milk products - median was $2.2(0-4)$ for people with partner and $3.5(0-7)$ for people without a partner $-p<0.05]$. In addition, another significant difference was observed when the participants were grouped according to sex [for question Specific Food sub-item 2.1 Eating five or more servings of fruits and/or vegetables - median 4.0 (3-7) male and 7.0 (3-7) female $\mathrm{p}<0.05$ and for question Foot-care (sub-item 5.3 Dry the spaces between the toes, after washing them) median 7.0 $(0-7)$ men and $5.0(0-7)$ women $-\mathrm{p}<0.05]$.

In relation to the difference between sex, it has been reported that the incidence of non-traumatic LLA in males with T2DM is three times higher when compared to females with $\mathrm{T} 2 \mathrm{DM},{ }^{17}$ which is in agreement with our observations since $63 \%$ of patients were male. In addition, it is noteworthy to point out that the male have a worsened in the DM year after year, as seen by the increase in LLC among male groups between 2000 and 2017, ${ }^{18}$ which could be an indicator of lower self-care in men. A recent study argued that differences in male and female behavior should be considered, because men are often under a greater physical burden and more social pressure than women, which may be a cause for lead them to feel the need to appear to be healthy and strong, ${ }^{19}$ possibly supporting the difference verified between men and women. However, for "Foot care" the women demonstrated better self-care, which does not agree with what we expected. It is important to highlight that despite the statistical difference, the median number of days that men reported foot care represents the majority of the days of the week, which means that this task is performed by both sexes. It is known that foot care involves more than performing care 
Table I Characteristics of Type 2 Diabetes Patients According to Sex, Marital Status, and Previous Amputation

\begin{tabular}{|c|c|c|c|c|c|c|}
\hline \multirow[t]{2}{*}{ Variables } & \multicolumn{2}{|c|}{ Sex } & \multicolumn{2}{|c|}{ Marital Status } & \multicolumn{2}{|c|}{ Previous Amputation } \\
\hline & Men $(n=65)$ & Women $(n=4 I)$ & With Partner $(n=56)$ & Without Partner $(n=50)$ & Yes $(n=4 I)$ & No $(n=65)$ \\
\hline \multicolumn{7}{|l|}{ Sex } \\
\hline Men & 65 & 0 & 41 & 24 & 26 & 39 \\
\hline Women & 0 & 41 & 15 & 26 & 15 & 26 \\
\hline \multicolumn{7}{|l|}{ Age } \\
\hline & $59.6 \pm 10.7$ & $66.8 \pm 15.2$ & $60.3 \pm 11.6$ & $61.3 \pm 13.7$ & $66.2 \pm 12.6$ & $57.5 \pm 12.8$ \\
\hline \multicolumn{7}{|l|}{ Ethnicity/color } \\
\hline White & 55 & 38 & 48 & 45 & 37 & 56 \\
\hline Black & 10 & 3 & 8 & 5 & 4 & 9 \\
\hline \multicolumn{7}{|l|}{ Work occupation } \\
\hline Ex-service & 26 & 25 & 27 & 24 & 23 & 28 \\
\hline Active worker & 18 & 7 & 15 & 10 & 6 & 19 \\
\hline Out-of-work & 13 & 3 & 5 & 11 & 8 & 8 \\
\hline Sick leave by doctor & 8 & 2 & 15 & 4 & 4 & 6 \\
\hline Home Worker & 0 & 4 & 3 & 1 & 0 & 4 \\
\hline \multicolumn{7}{|l|}{ SAH } \\
\hline Yes & 42 & 35 & 39 & 38 & 33 & 44 \\
\hline No & 23 & 6 & 17 & 12 & 8 & 21 \\
\hline \multicolumn{7}{|l|}{ Smoking } \\
\hline Yes & 5 & I & 2 & 4 & 3 & 3 \\
\hline No & 60 & 40 & 54 & 46 & 38 & 62 \\
\hline \multicolumn{7}{|l|}{ Years of diagnosis } \\
\hline$<1$ year & 2 & 3 & I & 4 & 0 & 5 \\
\hline I to 5 years & 7 & 3 & 7 & 4 & 4 & 7 \\
\hline 6 to 10 years & 16 & 14 & 16 & 15 & 14 & 17 \\
\hline$>10$ years & 40 & 21 & 32 & 27 & 23 & 36 \\
\hline \multicolumn{7}{|l|}{ Amputation level } \\
\hline Pododactyls & 30 & 22 & 28 & 24 & 17 & 35 \\
\hline Transmetatarsal & 25 & 7 & 19 & 13 & 11 & 21 \\
\hline Transtibial & 7 & 5 & 6 & 6 & 7 & 5 \\
\hline Transfemoral & 3 & 7 & 3 & 7 & 6 & 4 \\
\hline
\end{tabular}

Notes: Data presented in absolute values. Only age is presented as mean and standard deviation.

Abbreviation: $\mathrm{SAH}$, systolic arterial hypertension.

tasks, highlighting the knowledge, attitudes and practices of patients with diabetic and amputated feet. ${ }^{20,21}$

Family, economic, and working conditions, along with health system-related factors are the most important elements in the care of patients with diabetes and amputations. $^{20}$ In fact, support from family members and friends can be an important source of self- management support, ${ }^{21}$ and can putatively explain our findings regarding the difference in the more positive diet when considering marital status comparing patients who live with or without a partner, since forty-four percent of US adults help a family member or friend with chronic disease management and another $9 \%$ are willing to start. $^{21,22}$ 


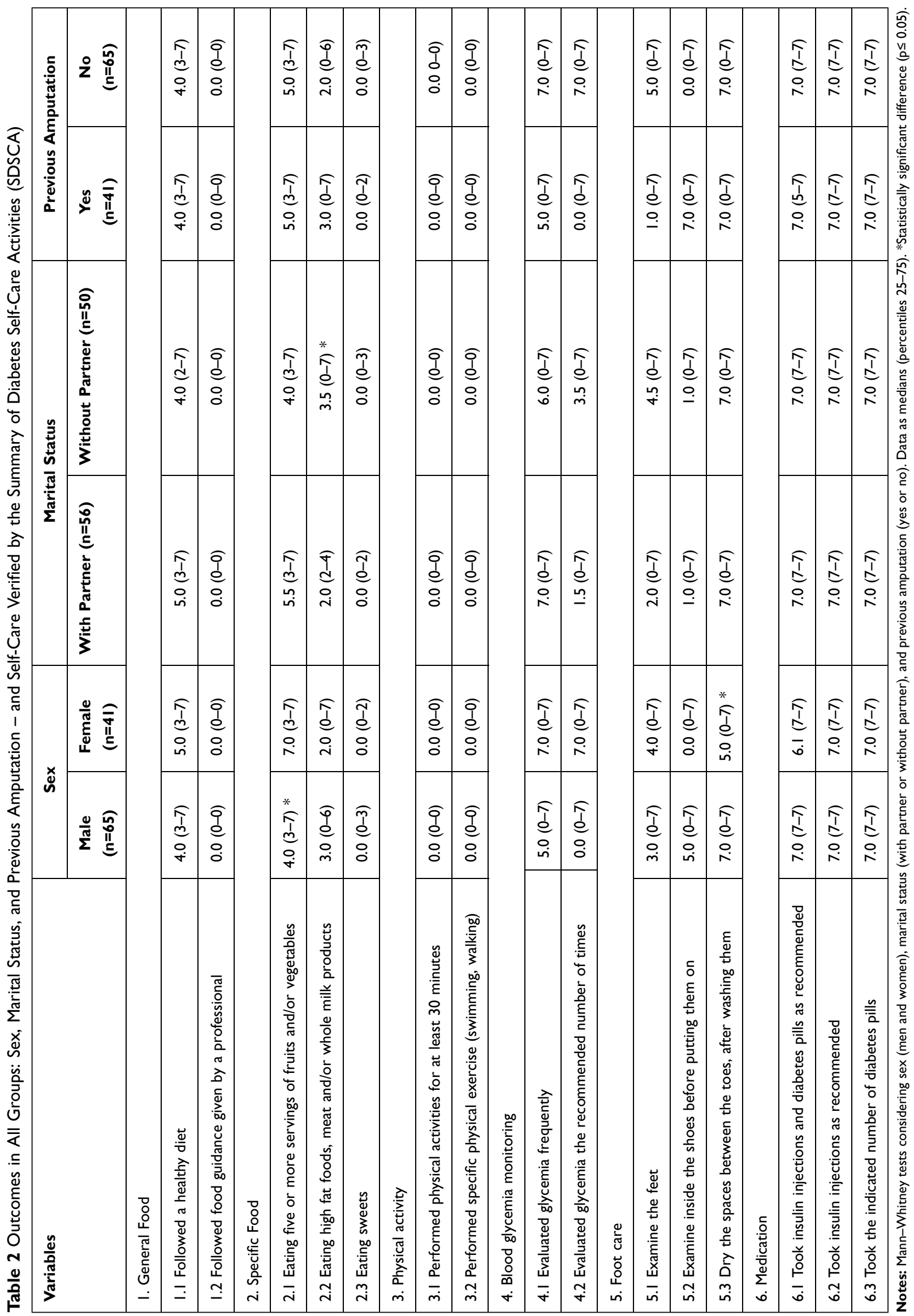


Table 3 Logistic Regression Concerning the Self-Care Variables Verified by the Summary of Diabetes Self-Care Activities (SDSCA)

\begin{tabular}{|c|c|c|c|c|c|c|c|c|c|c|c|c|}
\hline \multirow[t]{2}{*}{ Dichotomous Variable } & \multicolumn{4}{|c|}{ Sex } & \multicolumn{4}{|c|}{ Age } & \multicolumn{4}{|c|}{ Partner } \\
\hline & $\beta$ & SE & Wald & $\mathbf{P}$ & $\beta$ & SE & Wald & $\mathbf{P}$ & $\beta$ & SE & Wald & $\mathbf{P}$ \\
\hline I.I Followed a healthy diet & 0.276 & 0.424 & 0.422 & 0.516 & 0.001 & 0.016 & 0.003 & 0.958 & -0.112 & 0.401 & 0.079 & 0.779 \\
\hline $\begin{array}{l}\text { I.2 Followed food guidance given } \\
\text { by a professional }\end{array}$ & -0.280 & 0.761 & 0.135 & 0.713 & -0.003 & 0.029 & 0.009 & 0.926 & -0.626 & 0.743 & 0.709 & 0.400 \\
\hline $\begin{array}{l}\text { 2.I Eating five or more servings } \\
\text { of fruits and/or vegetables }\end{array}$ & 0.919 & 0.456 & 4.052 & 0.044 & 0.007 & 0.016 & 0.182 & 0.669 & -0.796 & 0.420 & 3.596 & 0.058 \\
\hline $\begin{array}{l}\text { 2.2 Eating high fat foods, meat } \\
\text { and/or whole milk products }\end{array}$ & -0.300 & 0.440 & 0.464 & 0.496 & 0.003 & 0.016 & 0.025 & 0.875 & 0.908 & 0.414 & 4.813 & $0.028^{*}$ \\
\hline 2.3 Eating sweets & -0.578 & 0.663 & 0.759 & 0.384 & -0.007 & 0.023 & 0.099 & 0.753 & 1.207 & 0.636 & 3.602 & $0.058^{*}$ \\
\hline $\begin{array}{l}\text { 3.I Performed physical activities } \\
\text { for at least } 30 \text { minutes }\end{array}$ & -0.463 & 0.734 & 0.398 & 0.528 & 0.019 & 0.026 & 0.517 & 0.472 & -0.591 & 0.677 & 0.762 & 0.383 \\
\hline $\begin{array}{l}\text { 3.2 Performed specific physical } \\
\text { exercise (swimming, walking) }\end{array}$ & 0.574 & 0.855 & 0.451 & 0.502 & 0.051 & 0.034 & 2.246 & 0.134 & -0.421 & 0.825 & 0.260 & 0.610 \\
\hline 4.I Evaluate glycemia frequently & 0.122 & 0.421 & 0.084 & 0.772 & -0.016 & 0.016 & 1.013 & 0.314 & 0.096 & 0.401 & 0.057 & $0.81 \mathrm{I}$ \\
\hline $\begin{array}{l}4.2 \text { Evaluate glycemia frequently } \\
\text { according to recommendations }\end{array}$ & 0.276 & 0.419 & 0.435 & 0.509 & -0.030 & 0.016 & 3.257 & 0.071 & 0.182 & 0.403 & 0.205 & 0.651 \\
\hline 5.I Examine the feet & 0.052 & 0.413 & 0.016 & 0.899 & -0.004 & 0.016 & 0.075 & 0.784 & 0.167 & 0.393 & 0.181 & 0.670 \\
\hline $\begin{array}{l}5.2 \text { Examine inside the shoes } \\
\text { before putting them on }\end{array}$ & -0.500 & 0.420 & 1.416 & 0.234 & -0.003 & 0.016 & 0.032 & 0.859 & -0.169 & 0.397 & 0.180 & 0.671 \\
\hline $\begin{array}{l}\text { 5.3 Dry the spaces between the } \\
\text { toes, after washing them }\end{array}$ & -0.709 & 0.432 & 2.692 & 0.101 & -0.004 & 0.017 & $0.07 \mid$ & 0.789 & -0.430 & 0.414 & 1.080 & 0.299 \\
\hline $\begin{array}{l}\text { 6.I Took insulin injections and } \\
\text { diabetes pills as recommended }\end{array}$ & -0.252 & 0.435 & 0.335 & 0.563 & -0.024 & 0.017 & 2.081 & 0.149 & -0.568 & 0.415 & 1.872 & 0.171 \\
\hline $\begin{array}{l}6.2 \text { Took insulin injections as } \\
\text { recommended }\end{array}$ & 0.571 & 0.522 & 1.199 & 0.274 & 0.003 & 0.019 & 0.026 & 0.871 & 1.472 & 0.532 & 7.647 & $0.006 *$ \\
\hline $\begin{array}{l}6.3 \text { Took the indicated number of } \\
\text { diabetes pills }\end{array}$ & 0.237 & 0.437 & 0.294 & 0.588 & 0.018 & 0.017 & 1.112 & 0.292 & -0.478 & 0.421 & 1.291 & 0.256 \\
\hline 7.I Smoked in the last week & 1.273 & 1.158 & 1.210 & 0.271 & 0.007 & 0.032 & 0.047 & 0.828 & -1.847 & 1.126 & 2.687 & 0.101 \\
\hline $\begin{array}{l}7.2 \text { Smoked more than } 10 \\
\text { cigarettes in the last week }\end{array}$ & 1.273 & 1.158 & 1.210 & 0.271 & 0.007 & 0.032 & 0.047 & 0.828 & -1.847 & 1.126 & 2.687 & 0.101 \\
\hline
\end{tabular}

Notes: ANOVA test. *Statistically significant difference $(p \leq 0.0 .05)$.

The logistic regression analysis showed that Marital Status presented significance $(\mathrm{p}=0.028)$ in item 2: Specific Food, for sub-item 2.2: Eating high-fat food meat and/or whole milk products and a tendency $(p=0.058)$ for sub-item 2.3: Eating sweets. Taken together, these observations reaffirm the importance of self-care in relation to food in the verified sample.
Another point that renders attention in the T2DM patients is associated to the fact that a prior minor amputation is associated with an increase of ten-fold the risk of a subsequent major amputation, which can also lead to an increase in the risk of another minor amputation by 20 times. ${ }^{23}$ Transmetatarsal amputations have generally been accepted as a relatively more definitive amputation 
compared with other lesser ray resections. ${ }^{23}$ In this respect, our observation that patients with or without a previous amputation did not differ in terms of self-care can indicate that the later reamputation may in fact be related to complications from a previous amputation.

In addition to the comparisons between the groups shown in Table 2, it is important to highlight that none of the T2DM patients reported practicing physical activity on any day of the week [sub-item 3.1. Performed physical activities for at least 30 minutes and 3.2 Performed specific physical exercise (swimming, walking)]. It is widely accepted that physical activity is an important variable to decrease the risk for chronic disease, ${ }^{24,25}$ and an inverse association between physical activity and risk of T2DM has already been established. ${ }^{26}$

This study has some limitations. First, a generalization of the results to larger populations and comparisons with other populations can be difficult because our sample is small. Second, the use of biological variables would represent an advance, especially to describe the mechanisms involved in self-care in T2DM patients with urgency lower limb amputation. Another limitation of our study is related to reasons for not having a partner. We do not have the information if patients who lived alone were not married or they were widowed. In addition, despite the fact that the patients are being treated at a public hospital, which may indicate a lower socioeconomic population, this information was not investigated (income). These two points can lead to poor diet and cannot be explored in the present study. Finally, indications for previous LLA where they exist were not reported, which could represent an important bias.

\section{Conclusion}

The self-care in T2DM patients submitted to urgency LLA, verified using the SDSCA, presented differences in sex and marital status when these parameters were associated with "Specific Food" and "Foot care" questions. In fact, men had worse consumption of fruits and vegetables when compared to women. On the other hand, men showed more days of care in relation to dry the spaces between the toes. Regarding marital status, patients who live with partner have a better standard of food consumption eating less high fat foods, meat and/or whole milk products than patients who live without partner. This information is important for multidisciplinary teams to develop management and interventions to prevent the need for urgency LLA in T2DM patients.

\section{Acknowledgments}

To the patients and institutions involved in research.

\section{Disclosure}

The authors received support from Fapesp: André Luis Lacerda Bachi - FAPESP 19/14115-0; Carolina Nunes França - FAPESP 17/01368-2 and 19/01020-1; and Lucas Melo Neves - FAPESP 20/08869-0. The authors report no other conflicts of interest in this work.

\section{References}

1. Ogurtsova K, da Rocha Fernandes J, Huang Y, et al. IDF Diabetes Atlas: global estimates for the prevalence of diabetes for 2015 and 2040. Diabetes Res Clin Pract. 2017;128:40-50. doi:10.1016/j. diabres.2017.03.024

2. Menke A, Orchard TJ, Imperatore G, et al. The prevalence of type 1 diabetes in the United States. Epidemiology (Cambridge, Mass). 2013;24(5):773. doi:10.1097/EDE.0b013e31829ef01a

3. Control CfD, Prevention. National center for chronic disease prevention and health promotion, division of nutrition, physical activity, and obesity. Data, Trend Maps. 2018.

4. Lin X, Xu Y, Pan X, et al. Global, regional, and national burden and trend of diabetes in 195 countries and territories: an analysis from 1990 to 2025. Sci Rep. 2020;10(1):14790. doi:10.1038/s41598-020-71908-9

5. Zhang P, Lu J, Jing Y, et al. Global epidemiology of diabetic foot ulceration: a systematic review and meta-analysis. Ann Med. 2017;49 (2):106-116. doi:10.1080/07853890.2016.1231932

6. Garcia M, Hernandez B, Ellington TG, et al. A lack of decline in major nontraumatic amputations in Texas: contemporary trends, risk factor associations, and impact of revascularization. Diabetes Care. 2019;42(6):1061-1066. doi:10.2337/dc19-0078

7. Lin C-W, Armstrong DG, Lin C-H, et al. Nationwide trends in the epidemiology of diabetic foot complications and lower-extremity amputation over an 8-year period. BMJ Open Diabetes Res Care. 2019;7(1):e000795. doi:10.1136/bmjdrc-2019-000795

8. Li C-I, Cheng H-M, Liu C-S, et al. Association between glucose variation and lower extremity amputation incidence in individuals with type 2 diabetes: a nationwide retrospective cohort study. Diabetologia. 2020;63(1):194-205. doi:10.1007/s00125-019-05012-7

9. Narres M, Kvitkina T, Claessen H, et al. Incidence of lower extremity amputations in the diabetic compared with the non-diabetic population: a systematic review. PLoS One. 2017;12(8):e0182081. doi:10.1371/ journal.pone. 0182081

10. Jeffcoate WJ, Harding KG. Diabetic foot ulcers. The Lancet. 2003;361(9368):1545-1551. doi:10.1016/S0140-6736(03)13169-8

11. ADA. 11. Microvascular complications and foot care: standards of medical care in diabetes-2019. Diabetes Care. 2019;42(Supplement 1):S124-S38. doi:10.2337/dc19-S011

12. Amorim MMA, de Souza AH, Coelho AK. Competences for self-care and self-control in diabetes mellitus type 2 in primary health care. World J Diabetes. 2019;10(8):454-462. doi:10.4239/wjd.v10.i8.454

13 ADA-Educators. An effective model of diabetes care and education: revising the AADE7 Self-Care Behaviors $\left({ }^{\circledR}\right)$. Diabetes Educ. 2020;46 (2):139-160. doi:10.1177/0145721719894903.

14. Sen P, Demirdal T, Emir B. Meta-analysis of risk factors for amputation in diabetic foot infections. Diabetes Metab Res Rev. 2019;35(7): e3165. doi:10.1002/dmrr.3165

15. Toobert DJ, Hampson SE, Glasgow RE. The summary of diabetes self-care activities measure: results from 7 studies and a revised scale. Diabetes Care. 2000;23(7):943-950. doi:10.2337/ diacare.23.7.943 
16. Michels MJ, Coral MHC, Sakae TM, et al. Questionário de Atividades de Autocuidado com o Diabetes: tradução, adaptação e avaliação das propriedades psicométricas. Arquivos Brasileiros De Endocrinologia \& Metabologia. 2010;54:644-651. doi:10.1590/ S0004-27302010000700009

17. Gandhi SK, Waschbusch M, Michael M, et al. Age- and sex-specific incidence of non-traumatic lower limb amputation in patients with type 2 diabetes mellitus in a U.S. claims database. Diabetes Res Clin Pract. 2020;169:108452. doi:10.1016/j.diabres.2020.108452

18. Harding JL, Andes LJ, Rolka DB, et al. National and state-level trends in nontraumatic lower-extremity amputation among US medicare beneficiaries with diabetes, 2000-2017. Diabetes Care. 2020;43 (10):2453-2459. doi:10.2337/dc20-0586

19. Sayiner ZA, Can FI, Akarsu E. Patients' clinical characteristics and predictors for diabetic foot amputation. Prim Care Diabetes. 2019;13 (3):247-251. doi:10.1016/j.pcd.2018.12.002

20. Hanley G, Chiou PY. Foot care knowledge, attitudes and practices among patients with diabetic foot and amputation in St. Kitts and Nevis. 2020;17(5):1142-1152. doi:10.1111/iwj.13446

21. Bonner T, Guidry J, Jackson Z. Association between foot care knowledge and practices among African Americans with Type 2 diabetes: an exploratory pilot study. J Natl Med Assoc. 2019;111(3):256-261. doi:10.1016/j.jnma.2018.10.004
22. Lee AA, Piette JD, Heisler M, et al. Family members' experiences supporting adults with chronic illness: a national survey. Fam Syst Health. 2017;35(4):463-473. doi:10.1037/fsh0000293

23. Gurney JK, Stanley J, York S, et al. Risk of lower limb amputation in a national prevalent cohort of patients with diabetes. Diabetologia. 2018;61(3):626-635. doi:10.1007/s00125-017-4488-8

24. Bull FC, Al-Ansari SS, Biddle S, et al. World Health Organization 2020 guidelines on physical activity and sedentary behaviour. $\mathrm{Br}$ $J$ Med. 2020;54(24):1451-1462. doi:10.1136/bjsports-2020-102955

25. Piercy KL, Troiano RP, Ballard RM, et al. The physical activity guidelines for Americans. JAMA. 2018;320(19):2020-2028. doi:10.1001/jama.2018.14854

26. Aune D, Norat T, Leitzmann M, et al. Physical activity and the risk of type 2 diabetes: a systematic review and dose-response meta-analysis. Eur J Epidemiol. 2015;30(7):529-542. doi:10.1007/ s10654-015-0056-Z
Patient Preference and Adherence

\section{Publish your work in this journal}

Patient Preference and Adherence is an international, peer-reviewed, open access journal that focusing on the growing importance of patient preference and adherence throughout the therapeutic continuum. Patient satisfaction, acceptability, quality of life, compliance, persistence and their role in developing new therapeutic modalities and compounds to optimize clinical outcomes for existing disease

\section{Dovepress}

states are major areas of interest for the journal. This journal has been accepted for indexing on PubMed Central. The manuscript management system is completely online and includes a very quick and fair peer-review system, which is all easy to use. Visit http:// www.dovepress.com/testimonials.php to read real quotes from published authors. 